\title{
LAS NUEVAS DEMANDAS DE SEGURIDAD
}

RAFAel JimÉnez VegA

\section{Resumen}

El contexto actual global, con un mundo interconectado que ha obviado los obstáculos geográficos, ha creado amenazas para la seguridad de los Estados, que ya venían teniendo serios problemas para administrar los riesgos desde que la seguridad se tornó humana, con la demanda de protección por parte de la población en todos los aspectos de la seguridad social, entendiendo que si estos no eran solventados no se podría garantizar la convivencia. Esto entra en vigencia en la década de los setenta del siglo xx, cuando los Estados de bienestar comienzan a tener una variación producto de la incapacidad de seguir solventando este gasto público, de ahí que al aunarse los retos de la globalización, surge la necesidad de vincular la franja de lo social para que mediante la solidaridad, la acción comunicativa y la profilaxis de sus comportamientos, se construya comunidad.
Palabras clave: Estado, seguridad, globalización, convivencia, crimen.

\section{THE NEW SECURITY DEMANDS}

\begin{abstract}
The current global context with an interconnected world that has ignored geographical obstacles, has created threats to the security of states. They were already having serious problems managing security risks since these became human, demanding of them the protection of the population in all aspects of social security, with the understanding that if these were not solved coexistence could not be guaranteed. This started in the nineteenseventies, when welfare states began to have variations, which were a product of their inability to continue paying for this public spending. Thus, with the challenges of globali-
\end{abstract}

* Oficial en el Grado de Coronel de la Policía Nacional. Candidato a Doctor en Estudios políticos, Universidad Externado de Colombia, Bogotá (Colombia).rafaeljimenezv68@hotmail.com

Recibido: 3 de octubre de 2015 / Modificado: 9 de noviembre de 2015 / Aceptado: 19 de noviembre de 2015.

Para citar este artículo

Jiménez Vega, R. (2015). Las nuevas demandas de seguridad. OPERA, 17, pp. 127-147. DOI: http://dx.doi. org/10.18601/16578651.n17.07 
zation, the need arose to link the social fringe, so that community could be built through social solidarity, communicative action, and preventive behavior.

Key words: State, security, globalization, coexistence, crime.

$\mathrm{Al}$ analizar la interpretación que las teorías de las relaciones internacionales le han dado a los diferentes momentos históricos, se aprecia el paso de un liberalismo a un realismo descrito por Hans Morgenthau como un sistema internacional de ganancias absolutas, que determinaba crudamente quién ganaba y quién perdía, sin que los ciudadanos tuvieran mayor participación en las estrategias de seguridad. De esta manera, se impusieron unos modelos de seguridad después del periodo de guerras mundiales, bajo el contexto de la Guerra Fría, dentro de un concepto realista en el que se enfrentaban los dos bandos en contienda guiados por los dos grandes hegemones, Estados Unidos y la Unión Soviética. Sin embargo, con la exigencia del cumplimiento de los derechos humanos y el nuevo constitucionalismo, los modelos de seguridad fueron dando un giro. Por ello, el nuevo enfoque neoliberal propuesto por Keohane y Nye en la década de los setenta, termina reflejando que el poder de una manera foucaultiana, ya no solo está en los Estados, sino que los diferentes actores que se encuentran en el escenario internacional como la sociedad civil, deben ser tenidos en cuenta en la toma de decisiones y en el planteamiento de las estrategias de los gobiernos, algo que terminaría reconociendo el neorrealismo con Kenneth Waltz, haciendo que los conceptos de seguridad se orienten hacia los intereses ciudadanos.

Esto conlleva, en la década de los noventa del siglo $\mathrm{xx}$, a que ante las diferentes demandas emergentes, como la preocupación por el medioambiente, los medios de comunicación, el cumplimiento de los derechos sociales y políticos, las reivindicaciones culturales y el reconocimiento de la diferencia, se haga obligatorio asumir un enfoque funcional del contexto de la seguridad, porque al ser porosas las fronteras de los Estados, estos se ven en la obligación de asociarse para así poder aplicar estrategias efectivas contra el crimen y las diferentes conductas desviadas que se puedan evidenciar en los ciudadanos del mundo. Incluso estas estrategias, para que sean eficaces, deben incluir a la sociedad civil y a todas las personas del común para que a través del compromiso, cada uno de los actores ayude a construir la convivencia.

Sin lugar a dudas, las nuevas demandas de seguridad han rebasado la capacidad del Estado, porque este ente, por sí solo, ya no está en capacidad de garantizar de manera unilateral la convivencia desde que el concepto abarca, no solo lo físico, sino que compromete al Estado en el cumplimiento de los derechos sociales, provocando que surjan factores adicionales que atender, sumándole a esta eventualidad la globalización con los medios de comunicación, que han añadido otros factores, lo cual ha hecho necesario que para satisfacer esta necesidad prioritaria, se deba optar por acudir a la Escuela Crítica a fin de articular las franjas pública, privada y social para construir convivencia. 
Todo esto se ha dado en un proceso de transformación acelerado del contexto social, que viene siendo evidente desde la década de los sesenta del siglo $\mathrm{xx}$, con el jipismo y con los movimientos juveniles europeos, incidiendo en la construcción de un individualismo dentro de la sociedad que cada vez clama más por el reconocimiento de la diferencia y por el respeto de la identidad. Algo que Byung-Chul Han (2014, p. 31) interpreta como una creciente tendencia al egoísmo y a la atomización de la sociedad, provocando que se encojan los espacios para la acción común y solidaria. Lo anterior se complica más, cuando también hay que atender una criminalidad que tiende a desbordarse al manifestarse de múltiples maneras, a lo que se le adiciona la necesidad de proteger los derechos humanos y el medioambiente, tan afectado por la explotación indiscriminada de los recursos naturales y por los procesos industriales, así como por la falta de conciencia y colaboración de las personas.

De esta manera, se hace necesario construir algo que Michel Foucault (2014, p. 115) ha llamado régimen de verdad, que obliga a los individuos a realizar actos de verdad, es decir, los principios de policía del buen gobierno deben motivar a las personas a realizar actos que vayan en concordancia con las políticas públicas implementadas; en términos de Douglas North (North, 1993), las instituciones formales deben coincidir con las informales, vinculando de esta manera a la sociedad y a los individuos como recurso indispensable para que las necesidades de seguridad sean satisfechas, creando obligaciones de los individuos en procedimientos de manifestación de lo verdadero. Ya no es suficiente el buen gobierno de los Estados (buena policía), ahora se requiere también el buen autogobierno de los individuos y de su solidaridad; en palabras de Mauricio Malagón (2007), que cada persona practique una buena policía (buen autogobierno).

Para explicar lo enunciado, se procede a mostrar las variables analizadas comenzando por la conformación inicial de la seguridad desde el Estado dentro de un contexto realista, para ir trascendiendo a un modelo liberal de alianza entre lo público y lo privado que va a ser eficiente hasta la década de los setenta del siglo xx, que Keohane y Nye describen como un neoliberalismo dentro de las relaciones internacionales, en donde la sociedad civil y, por supuesto, lo social, comienzan a ser prioritarios, conllevando la obligatoria participación ciudadana en la construcción de la convivencia; a esto se aúna el momento de globalización que acelera los procesos de cambio social, político y económico, entre los que se encuentran inmersos los derechos humanos y la preocupación por la protección del medioambiente.

\section{CONTEXTO DE LA SEGURIDAD AL INTERIOR DE LOS ESTADOS}

En un mundo donde la protección de los individuos se hace obligatoria y lo social es cada vez más preponderante, se torna imperativo que los enfoques y las estrategias de seguridad sean cada vez más eficientes, certificando de esta manera, que los ciudadanos pueden pensar en cumplir sus proyectos de vida sin estar expuestos a ser víctimas de algún delito. Para Jacques Chevallier (2011, p. 97), 
el mantenimiento del orden constituyente es una de las funciones principales del Estado, pero esta misión abarca una amplia problemática, porque una seguridad fundada sobre la idea de protección de los individuos contra riesgos de toda índole, significa extremar las capacidades de las organizaciones destinadas para tal fin, porque constantemente están surgiendo nuevas amenazas, provocando la movilización de los diferentes niveles de intervención y contribución.

En este orden de ideas, se debe recordar cómo se fue conformando la seguridad, comenzando por aquella creada desde el realismo como un modelo descrito por Weber y Foucault, que maximizó la vigilancia para controlar a la población; Enzensberger (1987, p. 11) señala que esto fue lo que ocurrió desde un comienzo, porque entre el asesinato y la política existe una dependencia antigua, estrecha y oscura, que parte del origen del Estado cuando quien tenía el poder podía dar muerte a los súbditos. Desde ese momento, no ha habido revolución que haya renunciado a dar muerte al antiguo gobernante, recayendo el poder del tirano muerto sobre sus asesinos. De ahí que toda muerte por el hombre sea tolerada, pero solo en casos extremos, describiéndose así que la historia del derecho es una escisión de la esfera política, porque todas las disposiciones legales son una protección frente al poder y al mismo tiempo su instrumento. De esta manera, el crimen y la política crean un vínculo como manifestación de la completa independencia del Estado de todo otro poder, porque este es connatural a él, por lo que se encuentra por encima de toda legislación como manifestación de su soberanía, prohibiendo al individuo hacer uso de la injusticia, porque la esencia del Estado no admite poderes superiores; de esta forma, a través de la ley, se crearon las condiciones para que una sociedad se sienta más segura de sus previsiones.

Fue así como se comenzaron a controlar los impulsos egoístas de los seres humanos que, mediante acciones premeditadas, decidían participar en actividades prohibidas. Es por ello que, desde un comienzo, se estableció por el Estado la creación de controles sobre todos los actos que atentaran contra el derecho penal, denominando crimen al desacato o incumplimiento de las reglas de conducta a las que la generalidad considera como obligatorias (Enzensberger, 1987, p. 7).

Después del periodo de guerras mundiales del siglo xx, se creó un vacío que fue colmado por el sector privado, formándose una alianza entre lo privado y lo público para hacer frente a las amenazas que surgieron en el periodo del posconflicto, conformando un modelo liberal de la seguridad, que entre otras cosas, estuvo acompañado de un crecimiento económico sin precedentes, el cual finalizó en la década de los setenta, generó cambios en todos los órdenes y dio como resultado que lo social se convirtiera en una prioridad; por ello, la aparición de nuevas demandas da lugar a una nueva franja de lo social para que, junto con lo público y lo privado, satisfagan las nuevas exigencias. Aclara Bauman (2001, p. 24), que en este proceso ha resultado definitivo el apoyo de la comunidad, por ser quien realmente garantiza la no ocurrencia del delito o la afectación a las normas de convivencia, al no tolerar a las personas que atenten contra el orden social. Pero este concepto se dificulta 
cuando se debe implementar en una población heterogénea como la actual, en donde el cambio cultural se ha caracterizado por el ascenso de la cultura de la libertad (Castells, Caraça y Cardoso, 2013, p. 22), que para Byung-Chul Han (2014, p. 31) es un engaño, porque hoy en día cada ser humano se explota a sí mismo, acogiéndose a los estereotipos fijados por la sociedad, en busca de reconocimiento y autorrealización.

Ahora bien, dentro de esas particularidades enunciadas, Bauman (2001, p. 25) expone las principales condiciones para satisfacer la necesidad de seguridad de este heterogéneo panorama, de la siguiente manera: el poder ostentar sin temor la propiedad de los elementos materiales adquiridos; así como la certeza de que las personas que componen la comunidad sepan diferenciar, de acuerdo con sus costumbres y cultura, qué es lo correcto e incorrecto en las elecciones diarias que se deben asumir, liberando la cultura del miedo; y por último, que los ciudadanos, al actuar de manera correcta, se sientan protegidos de que ningún peligro extremo (algo de lo que no puedan defenderse) amenaza su integridad, la de sus familia y sus pertenencias. Estos factores permiten que el corazón de la vida política radique en un profundo e insaciable deseo de seguridad.

En esta dinámica, no se pueden obviar los medios tecnológicos, con la sensación de vértigo que impone su velocidad, haciendo del poder algo extraterritorial en el que el individuo debe enfrentarse a un rango cada vez más variado de exigencias de conducta, lo que provoca que el proceso de la autofabricación del yo nunca termine, porque en la individua- lidad todo puede ser posible e indeterminado, simplemente se debe respetar la singularidad siempre y cuando ella no atente contra el orden social. De acuerdo con Bauman (2001, p. 35), esto demanda una necesidad de flexibilidad para adaptarse a las cambiantes condiciones, y una transparencia que se refleja en el flujo de información de los medios informáticos, en donde todas las personas admiten voluntariamente ser controladas al incluir sus datos personales, sus hábitos y su perfil profesional, en rechazo a la individualidad y la libertad, en donde se crea un derecho a la publicidad que radica en hacer público todo aquello que despierte curiosidad, con la idea de ser el centro de interés, desmantelando con esto los modelos de seguridad construidos. De esta manera, los mecanismos productores de incertidumbre e inseguridad se deslocalizan y son de tipo global, y se ponen fuera del alcance de las instituciones formales.

Bauman (2001, p. 163) entiende, en consecuencia, que la meta de la democracia liberal es lograr una clase de sociedad capaz de ocuparse de que los asuntos del Estado sean manejados correctamente, y, por su parte, el Estado sea capaz de defender a la sociedad de los excesos en los que pueda incurrir su autonomía. Al respecto, Pierre Rosanvallon (2009, p. 75) colige que si bien las funciones policiales, judiciales y de defensa subsisten para proteger a los individuos, lo relevante hoy es contribuir a que las personas constituyan una sociedad que parta de la realidad de los agrupamientos y de las formas de solidaridad, cumpliendo el Estado una labor de "institutor de lo social", ya no como el poder de ordenamiento de una masa de individuos, 
sino como una fuerza de coordinación de una multiplicidad de servicios públicos funcionales y autónomos orientados al interés general.

\section{CAMBIOS SOCIALES Y ECONÓMICOS QUE CONDUJERON AL INDIVIDUALISMO}

Es en los años setenta del siglo xx, cuando las transformaciones que venían sucediendo se terminan de consolidar, dando fin al futuro promisorio al que muchos ciudadanos del mundo se habían aferrado, gracias a los casi treinta ańos de crecimiento que siguieron a la Segunda Guerra Mundial, crecimiento que había comenzado a declinar (Castel, 2010, p. 15). Con este modelo se creyó que el progreso social iba a mejorar con el paso del tiempo, pero lo que aconteció fue todo lo contrario; después del rompimiento de Bretton Woods por parte de Estados Unidos y la crisis del petróleo de 1973, todos los factores -o el hecho social total como lo describe Marcel Mauss-se vieron afectados y cambiaron.

De esta manera, a lo que se le dio el nombre de "tercera revolución industrial" por algunos autores en la década de los setenta, terminó por crear el escenario internacional que Keohane y Nye describieron en su momento. Este fenómeno se caracterizó por el adelanto tecnológico, que transformó el capitalismo industrial en un régimen capitalista, afectando la manera de producir, de intercambiar y los modos de regulación que se habían impuesto en el modelo anterior. Es debido a esta situación de cambio, que desde este momento el tema de las desigualdades se convierte en el corazón de la cuestión social (Castel, 2010, p. 16), como una de las causas de la inseguridad.
Algo que obedece, de acuerdo con Bob Jessop (1999, p. 21), al cambio del modelo de acumulación fordista, que crea una crisis del Estado como factor de regulación social, al quedar relegado únicamente a las labores de justicia y orden, y a las de garantizar un entorno sano para el funcionamiento de los mecanismos de mercado. Por tanto, los principales riesgos de la existencia humana, como enfermedad, desocupación, jubilación, invalidez, etc., variaron, de tal manera que al aumentar los riesgos, la técnica de seguros construidos en la modernidad dejó de ser eficiente.

Para Castel (2010, p. 19), este fenómeno se explica porque la sociedad salarial funciona a partir de la distinción, provocando un cambio en la relación laboral que ya no juega solamente entre individuos, sino que se traslada a las grandes categorías socioprofesionales homogéneas que componen la sociedad salarial, aspirando cada una a acercarse a la categoría del estrato superior y a alejarse del estrato que se encuentra debajo de ella. Ya no se trata de una lógica de oposición de clases, sino de una competencia entre grupos profesionales, que se capacitan cada vez más para establecer una diferencia, en busca de un reconocimiento y una independencia en su relación contractual.

$\mathrm{Al}$ respecto, Boaventura de Sousa Santos (2012, p. 13) señala que luego de la situación vivida respecto de los movimientos sociales y la democracia durante la década de los setenta, se transitó al decaimiento de los sindicatos y al pronunciamiento individual, porque cambiaron las condiciones contractuales entre las empresas y sus trabajadores. Las primeras no querían compromisos pensionales con sus empleados, y los segundos, no pretendían 
un compromiso que limitara su desarrollo profesional y la opción de acceder a mejores ofertas laborales, lo que condujo a un anhelo de libertad y de respeto por la singularidad, que desembocó en la demanda de los derechos sociales y con ello, al fin de los gobiernos de extrema derecha, del comunismo autoritario y del apartheid, produciéndose un efecto dominó que terminó poniendo fin al conflicto este-oeste.

En este proceso de transformación, Castel (2010, p. 22) encuentra una dinámica de descolectivización, es decir, que de un conjunto de sistemas de regulaciones colectivas, que en cierta forma garantizaban la redistribución de los recursos y la protección laboral, se transitó a un modelo de individualización creciente de las tareas, que exige la movilidad, la adaptabilidad y la asunción de responsabilidades por parte de los individuos, en que los trabajadores pasan a hacerse cargo de ellos mismos, y se omite la inscripción en las regulaciones colectivas del empleo estable. Algunos individuos se benefician de estas nuevas condiciones, maximizando sus posibilidades y se vuelven hipercompetitivos, dejando a un lado la situación que se presenta con otra categoría de individuos, que al tener menores competencias pasan a ser víctimas, quedando este grupo amenazado por la invalidación social, ya sea por la inexistencia de los soportes colectivos que les garantizaban cierta estabilidad, o porque no logran inscribirse en alguno. A este fenómeno, De Sousa Santos (2012, p. 163) lo llama el regreso del individuo, como producto del agotamiento de las estructuras que arbitraban la revalorización de las prácticas y los procesos laborales.
Esta individualización implica efectos contrastados, al maximizar las posibilidades de unos e invalidar las de otros (Castel, 2010, p. 27). Lo cierto es que, de acuerdo con lo expresado por Gerardo Pisarello (2007, p. 12), desde el punto de vista del comportamiento interno de los Estados, las actuaciones institucionales que hicieron viables los Estados sociales democráticos de derecho, los cuales pusieron en marcha políticas que compensaran los efectos excluyentes del desarrollo económico, fueron por lo común reacias a aceptar controles políticos, jurídicos y sociales sólidos, lo que las volvió abiertamente vulnerables al asalto de poderes privados y burocráticos.

Si se parte del hecho de que la política social se construye sobre la relación entre mercado, Estado y orden doméstico (Giraldo, 2013, p. 13), para crear una relación directa entre el orden político (Estado) y el orden doméstico, se aprecia que se han dejado espacios vulnerables que no son asistidos. Gerardo Pisarello (2007) señala que las medidas adoptadas han propiciado intervenciones selectivas, que en lugar de menguar o reducir las desigualdades, han tendido a aumentar, porque no han funcionado eficientemente como medidas para el control de la pobreza. Más bien, su exigibilidad ha permanecido relegada a las necesidades de los derechos civiles y políticos, pero sobre todo, a los derechos patrimoniales de propiedad privada y libertad de empresa. Por lo demás, en el ámbito laboral, se debe comprender que hoy en día la competencia es el fundamento de la dinámica social, como forma de obtención de calidad de vida, a lo cual se vinculan los aspectos trascendentales de la existencia humana, como son la educación, 
el ámbito religioso y el cultural. Según ByungChul Han (2012, p. 25), la sociedad del siglo XXI ya no es disciplinaria como lo expresaba Foucault, sino una sociedad de rendimiento, donde ya no hay sujetos de obediencia, sino sujetos de rendimiento (entre los cuales hay depresivos y fracasados) que, obsesionados por maximizar la producción, obvian el dominio externo, y hacen que la libertad y la coacción coincidan al asumir una "libertad obligada".

Esta situación ha venido acompañada del individualismo que libera de las jerarquías de los poderes absolutos, proclamando la igualdad y la autodeterminación, en donde el proyecto de vida se convierte en un asunto personal, que ya no depende, de acuerdo con César Giraldo (2013, p. 49), del papel que la sociedad le asigna al individuo, sino que este tiene que construir su propia historia, alcanzar sus metas, autorrealizarse, sin la preocupación por los demás, ni por los fines colectivos de la sociedad. Este autocentramiento del individuo crea procesos de individualización que conducen a la necesidad de promover la identidad de la persona, creando autoafirmación ante la pérdida de los soportes colectivos; por otro lado, se promueve un espíritu utilitarista que conduce a valorar a las personas y a las cosas en función de su satisfacción inmediata.

De esta manera, según Anthony Giddens (2002, p. 98), se rompen los marcos identitarios tradicionales, disolviendo y emergiendo nuevas pautas que la globalización impone, lo que obliga a vivir en una forma más abierta y reflexiva, respondiendo constantemente a un entorno cambiante, en un proceso continuo de creación y recreación de la propia identidad. Por eso, se pasa del discurso de la sociedad justa al de los derechos humanos, al derecho de los individuos a ser diferentes y a elegir y tomar a voluntad sus propios modelos de felicidad y estilo de vida. De esta forma, se privatizan los derechos y aparece una lógica de la supervivencia que hace demandas en varios sentidos, de grupos y personales, $\mathrm{o}$ surgen otras sin un eje articulador, permitiendo que la subjetividad consagre derechos que los grupos reivindican para diferenciarse de los demás (Giraldo, 2013, p. 52).

Pero en este individualismo, las sociedades modernas han construido un terreno de inseguridad, porque en este contexto los individuos han tenido que asumir sus propios riesgos y adquirir seguros en un mundo en el que Robert Castel (2010, p. 35) percibe un aumento de las incertidumbres, en el que cada quien debe asumir la responsabilidad de sus decisiones en medio de los riesgos que lo rodean, sin derecho a compensaciones, excepto las que confieren los seguros privados voluntarios. De esta manera, se entiende que los riesgos son gestionados por cada individuo, de acuerdo con su capacidad adquisitiva y sus preferencias. De esta forma, también la seguridad se ha privatizado, cada persona ha asumido la responsabilidad de autoprotegerse, lo que ha llevado a un comercio de cerraduras patentadas, alarmas antirrobo, cercas de alambres de púas, grupos vecinales de vigilancia y personal de seguridad, etc. En este contexto el Estado, en un esfuerzo coordinado con la empresa privada, acompaña este proceso reglamentándolo y asistiéndolo, protegiendo mediante este mecanismo de seguridad física a las personas y sus propiedades, con el compromiso de capturar a los criminales y 
de mantener las calles libres de ladrones, sin lograr satisfacer la demanda. Pero en medio de esto, también se le exige al Estado que su papel trascendental sea el de garantizar la vigencia y cumplimiento de los derechos humanos.

En ese contexto, también se admiten acciones intervencionistas mediáticas, en una actitud de compasión frente a la llamada población pobre o vulnerable, por despertar sentimientos morales que motivan la ayuda, que muchas veces se piensan como un compromiso personal que queda en el ámbito de lo privado, o es asumido por las empresas y algunas ONG en sus políticas de responsabilidad social, mejorando la imagen de ellas pero realmente no tiene un efecto relevante, porque no altera la desigualdad existente, por el contrario, la mantiene y perpetúa. Al respecto, César Giraldo (2013, p. 64) explica que para que exista este tipo de ayudas, como especie de caridad, es necesario que haya dos partes: la que da y la que recibe, para lo cual es imprescindible que exista la desigualdad.

Al hacer hincapié en este aspecto, Anthony Giddens (2002, p. 438) considera que en la actualidad la igualdad radica en el acceso universal a las oportunidades y en la importancia del pluralismo y de la diversidad de formas de vida, pero resulta que en las actuales condiciones, los derechos sociales se legitiman y se practican en una esfera distinta de la que surgieron, porque, como lo deja ver Jairo Alonso Bautista (2013, p. 211), el mercado es un sistema de relaciones que no reconoce las diferencias materiales como un problema esencial, lo cual crea inequidades. Ante esto, Adela Cortina (2005) reclama que lo primero que se debe cumplir en un contrato son los pactos, para así sellar relaciones de confianza, para lo cual se acude al derecho, a fin de establecer una relación entre el Estado y el ciudadano, en la que la obligación del Estado es el derecho del ciudadano, y el ciudadano, por su lado, tiene obligaciones con el Estado (Giraldo, 2013, p. 65). Considérese ahora, que dentro ese contrato surge lo que Bauman (2001, p. 83) llama "consumidores defectuosos", que quedan excluidos de la agenda establecida por el mercado, optando estos por asumir unas formas de vida proclives al delito.

Surge, de acuerdo con esto, la discusión sobre la ciudadanía, porque la carencia de oportunidades no permite a buena parte de la población vincularse al mercado, haciéndose vulnerable en el sentido de que carece de los instrumentos para afrontar los riesgos (Giraldo, 2013, p. 77).

Para Ulrich Beck (2008, p. 20), estos riesgos son una amenaza a la seguridad que hace percibir un futuro incierto lleno de obstáculos, en una sociedad que ha dejado de lado las utopías, y ya no está determinada por la religión, la tradición o la sumisión a la naturaleza. Aparece así el riesgo, por la velocidad y la radicalidad que acompaña los acelerados días presentes, adquiriendo un nuevo carácter, porque fallan los cálculos que lo predicen y su procesamiento institucional; frente este fenómeno, la cultura de los países juega un papel trascendental. Este riesgo, dada la conectividad de la globalización, se hace contagioso, transformando las desigualdades sociales al hacerse democrático, porque afecta por igual a ricos y pobres, y hace que el miedo condicione las vidas de las personas y de la seguridad, un bien primordial para la calidad de vida. 


\section{CAMBIOS EN EL CONTEXTO POLÍTICO EN CONSONANCIA CON LO SOCIAL}

Luigi Ferrajoli (2010, p. 27) observa que ha surgido un modelo de democracia constitucional, fruto del cambio radical de paradigma producido en los últimos cincuenta años acerca del papel del derecho. Se trata de cambios en el imaginario colectivo y en la cultura jurídica y política, más que en las instituciones del Estado, que se ven obligadas a ser más eficientes para cumplir con su misión. De esta manera, mediante la división de poderes y la garantía de los derechos fundamentales, se han edificado el derecho y la democracia como construcciones humanas que son, arraigadas en la cultura y la política de cada país, fortalecidas por la fuerza de los movimientos sociales y de la iniciativa individual.

Con base en ese Estado garantista, se debe hacer frente en el siglo XxI a los riesgos imprevisibles y las inseguridades fabricadas por la modernidad comentadas por Ulrich Beck (2008, p. 260), que han hecho que ninguna nación pueda solucionar sus problemas en solitario, ocasionando la creación de comunidades transnacionales, que muestran una inevitable interdependencia como requisito para alcanzar el objetivo de la estabilidad y la gobernabilidad nacional. Este nuevo contexto cambiante y dinámico, ha hecho que los cuatro tipos de políticas públicas que se han implementado hasta el momento, explicados por Navarro (2000, p. 54) como opciones de los países capitalistas desarrollados, a saber: el socialdemócrata, el demócrata-cristiano, el liberal y el dictatorial-conservadora hayan cambiado para adaptarse a las nuevas deman- das y contextos, donde surge una sociedad protagonista e individualista, que exige del Estado el cumplimiento de sus obligaciones garantistas, en donde la seguridad juega un papel fundamental al adquirir un carácter funcional, que indica que el desequilibrio de cualquier factor social, incide en las condiciones de este contexto, en el que la igualdad de oportunidades y el control social se hacen trascendentales para inhibir el delito.

Por tanto, se puede decir que la delincuencia y la desviación son el resultado de tensiones estructurales ante la falta de igualdad de oportunidades, a lo que se le suma la falta de regulación moral dentro de la sociedad. Anthony Giddens (2002, p. 272) destaca que allí donde las aspiraciones de los individuos y de los grupos sociales no coinciden con las recompensas disponibles, se presenta la disparidad entre los deseos y la realización de estos, motivando las conductas desviadas de algunos miembros. Esto se debe a que no hay igualdad de oportunidades para acceder a la educación, a la salud y a unas condiciones laborales estables que garanticen una cobertura universal de seguridad social de calidad.

Incluso los países con políticas socialdemócratas, que centraban su objetivo en la expansión de los derechos políticos y sociales a toda la población, como manera de protegerla frente a los riesgos establecidos durante el ciclo vital, debieron realizar cambios en el modelo, que ha obligado a ajustes fiscales ante la dificultad del Estado de seguir brindando los mismos servicios sociales; en los cristianodemócratas, al modificarse el rol de la mujer en la familia y en la sociedad, por tener que capacitarse e ingresar al mercado 
laboral de manera competitiva con anhelos de realización profesional y personal, produjo profundos cambios en la conformación familiar, que se trasladaron a los ámbitos social, político y económico; por último, las políticas liberales han sostenido estrategias de tipo residual y asistencial, en las que los beneficios dependen de la prueba de necesidad, aunque en Canadá y en Gran Bretańa se universalizaron los derechos sanitarios. Por lo demás, la mayoría de los países anglosajones siguen el modelo liberal en el que gran parte de los beneficios, incluso aquellos de carácter universal, se complementan con beneficios adquiridos en el mercado del trabajo por medio de la negociación colectiva, centrando el gasto público en los que más lo necesitan, dejando a las autoridades político-administrativas la definición de necesidad (Navarro, 2000, pp. 55-84).

Para Castel (2010, p. 125), estas situaciones han dado lugar a la individualización de las tareas y de la trayectoria profesional, porque en la actualidad la idea del derecho al trabajo demasiado rígido e invasor, se ha convertido en un obstáculo para luchar contra la desocupación, impidiendo una organización más fluida del mercado de trabajo. Lo que se acostumbra ahora es que el individuo debe tomar a su cargo el desenvolvimiento de su carrera profesional, sin vincularse formalmente con las organizaciones ligadas a la estabilidad laboral, lo que erosiona las redes de protección. A esto se le adiciona, la visión aportada por Gilles Lipovestky (2011, p. 8) sobre la inversión de lo existencial, al presentarse la disolución del estatus y las posiciones rígidas, que producen combinaciones inesperadas, desconocidas y extrańas, para crear un paisaje aleatorio, rico en singularidades complejas, que hacen del individuo el protagonista ávido de identidad, de diferencia, de conservación, de tranquilidad y de realización personal.

Esto es complementado por Arévalo, Ciro y Gutiérrez (2006, p. 182), quienes aducen que para que el sistema de protección social sea residual, se requiere que las sociedades cuenten con buena calidad en el trabajo e ingresos estables, que garanticen altos niveles de vida, haciendo de la producción social el resultado de diversas formas de interacción que se tejen en el seno de una colectividad. De esta manera, la ciudadanía plena pasa a adquirirse en la medida que los derechos sociales tienen como base la salarización de la fuerza de trabajo. Porque el proyecto democrático consiste en instituir una sociedad e individuos iguales, en la que se establezca un régimen de verdadera soberanía popular (Rosanvallon, 2009, p. 39). Por otra parte, se debe considerar que el Estado no lo puede todo y se debe instaurar una mayor continuidad entre la acción individual y la acción colectiva, que Pierre Rosanvallon (1995, p. 214) llama un reformismo del individuo que fortalezca los principios organizadores de la solidaridad, para ofrecer un marco satisfactorio en el cual pensar la situación de los excluidos.

\section{INCIDENCIA DE LOS CAMBIOS EN EL CONTEXTO DE LA SEGURIDAD}

Los problemas causados por los vacíos del Estado social, que no permiten que los postulados de la seguridad humana sean una realidad, han dado lugar a que individuos vean 
en el delito una oportunidad que les permita solucionar sus necesidades básicas, e incluso, mediante la lógica criminal, pensar que este mecanismo es una opción válida para obtener las recompensas que el sistema salarial no les permite. Por consiguiente, quedan una serie de individuos a la deriva, que desatan lo que Enzenberger (1994, p. 18) llama una forma de guerra civil en las metrópolis, que pasa a hacer parte de la vida cotidiana, tratándose esto de un proceso endógeno, que siempre inicia una minoría que impide la convivencia civilizada, lo que da lugar al surgimiento de contrapoderes que se oponen al poder político y que tratan de ganar una lucha por el poder simbólico, como requisito previo para cualquier proceso social y político que pretenda cambiar el orden imperante (Giraldo, 2013, p. 15). Para conseguir sus fines, utilizan la violencia que se desliga totalmente de las justificaciones ideológicas, sin importar el asesinato de indefensos campesinos, o aliarse con los cabecillas de organizaciones criminales o incluso con los servicios secretos del país; simplemente lo relevante para este tipo de personas es cumplir su cometido carente de contenido ideológico y de orientación, incluso perdiendo en este proceso la capacidad de distinguir entre la destrucción y la autodestrucción. Esta paulatina agudización de las contradicciones entre los grupos sociales, se complica al aumentar su anarquía, dejando un aura de inseguridad en la que se hace difícil la implementación de estrategias unilaterales por parte de los cuerpos de policía, al evidenciarse que los problemas sociales obedecen a situaciones estructurales, en donde solo la implementación de políticas públicas puede controlar las disfuncio- nes descritas anteriormente, como consecuencia de los cambios sociales, económicos y políticos.

En este escenario de constante cambio, debe observarse que el factor social se hace relevante dentro del Estado, haciendo que la cultura y los hábitos de los ciudadanos jueguen un papel trascendental, por cuanto la acción de un Estado garantista, que debe asumir su responsabilidad de protector y ejecutor de las políticas de los derechos humanos, en una sociedad multicultural en donde los individuos reclaman el reconocimiento a su diferencia, pero de la misma manera su protección, es insuficiente, por lo que se hace necesario que de ese conglomerando no solo se demande, sino que también sea oferente de seguridad a través de la profilaxis de su comportamiento. Es por esta razón, que al hacerse evidente la vulnerabilidad de la naturaleza humana, como aduce Adriana Cavarero (2009, p. 45), se hace obligatorio convocar a la responsabilidad colectiva en la construcción de la convivencia, transformando así la preocupación narcisista de la melancolía, en preocupación por los demás.

Este proceso se dificulta cuando la diferencia sin ideología y sin orientación también incluye un actor criminal, que Enzensberger (1994, p. 28) describe como un delincuente que ha perdido el interés por sí mismo, encaminándose incluso las masas de estos sujetos díscolos a su propia muerte, perdiendo radicalmente el sentido común y de discernimiento, que deja ver un total desinterés por el instinto de autoconservación. En lo político, el terror que antes era monopolio de los regímenes totalitarios, hoy reaparece como forma des- 
nacionalizada que convierte cualquier diferencia en riesgo mortal, hace parecer que la autodestrucción colectiva fuera el objetivo principal y crea una locura colectiva suicida que ha perdido de vista la categoría de futuro. Esas personas que actúan con base en supuestos fines superiores, en nombre de los cuales deciden matar o morir, hace diferente la problemática criminal del tiempo presente, en la que existen seres humanos que están dispuestos a morir luchando por nada, simplemente son motivos superfluos los que acompañan su actuar, como un equipo de fútbol o la simple pertenencia a una banda que no representa ninguna ideología.

Destaca Giddens (2002, p. 313), que cualquier sociedad que reconozca los valores de los seres humanos y sus distintas preocupaciones, debe encontrar un espacio para los individuos o grupos cuyas actividades no se adapten a las reglas que siguen la mayoría. Esto debido a que se ha demostrado estadísticamente, que en las sociedades donde se reconoce una amplia gama de libertades individuales y en las que se toleran actividades desviadas, las tasas de delincuencia violenta son bajas, teniendo un bajo desorden social. Pero como condición para que esto se cumpla debe haber justicia social, es decir, para que se cumpla este logro, se debe tener en cuenta que este orden se alcanza donde las desigualdades no son muy grandes, y en donde toda la población tiene igualdad de oportunidades de llevar una vida plena y satisfactoria. Por tanto, es indispensable que haya un equilibrio entre libertad e igualdad, para que las conductas desviadas no se orienten hacia fines socialmente destructivos.
Esto para evitar, como seńala Enzensberger (1994, p. 33), que se muestre un universo humano negativo en el cual haya posibilidad de que vaguen bombas vivientes, prototipo del Leviatán de la lucha de todos contra todos descrito por Hobbes. Esto provocaría que allí donde el Estado no tiene poder, las personas asuman su propia protección o se organicen para hacer frente al riesgo o la amenaza, creando la necesidad de recurrir a abstracciones y modelos, al observarse que los riesgos son un problema intrínseco de sistemas sociales, que a su vez crean nuevas inseguridades e incertidumbres (Beck, 2008, p. 264).

Este escenario se complica, al surgir nuevas formas de egoísmo que acompañan a la modernidad avanzada, algo que de acuerdo con Fernando Tenorio Tagle (2006, p. 249), ha provocado en los segmentos medios y altos de la sociedad indiferencia, aumentando la afectación del delito en los grupos subalternos, que reciben a su vez con actitud apática un trato discriminatorio por el sistema penal, e incluso por los medios de comunicación. Todo esto hace que se concluya que, indudablemente, es el factor social el que determina la eficiencia y la eficacia del sistema de la seguridad pública, porque como bien lo explica Francesc Torralba (2003, p. 45), para lograr la convivencia, la ciudad demanda que sus habitantes deban asumir una categoría ética, adoptando un determinado estilo de vida que cultiva determinadas virtudes, siendo la más destacada la civilidad. Lo que quiere decir que las personas, a partir de esta virtud, llegan a ser capaces de resolver sus diferencias y sus problemas mediante la palabra y el acuerdo, yendo más allá del cumplimiento de las normas, 
porque ello se considera una realidad tácita, mostrando en los pequeños detalles nobleza y amabilidad, y, además, aceptando un espacio plural dinámico con diferencias de hábitos y maneras de ser de otros. Incluso la civilidad es respetar el tiempo y los espacios de los demás, manteniendo una responsabilidad con todo lo público, por considerarlo como algo valioso al que hay que aportar y embellecer.

Por último, se puede decir en este aspecto, que la armonía y el consenso que genera la civilidad, hacen que la palabra y el diálogo lleven a que no se haga uso de los recursos judiciales a disposición, porque se es capaz de vivir y trabajar con personas diferentes en una ciudadanía multicultural. Colige Byung-Chul Han (2012, p. 22), señala que hoy en día se debe habitar en un espacio libre de negatividad de lo idéntico, donde no exista ninguna polaridad entre amigo y enemigo, entre el adentro y el afuera, o entre lo propio y lo extrańo. En lo cual, sin lugar a dudas, entran a jugar un papel trascendental las instituciones para Douglas North (1993, p. 59), porque son las reglas de juego que regulan las interacciones humanas, las cuales pueden ser formales (escritas) o informales (no están escritas), dependiendo del respeto de estas normas la construcción del capital social. Por tanto, se entiende que el capital social está ligado a las instituciones, siendo dentro de este marco que los agentes económicos realizan transacciones que le permiten al mercado cumplir de forma adecuada el papel asignador en el que los individuos maximizan sus preferencias. De esta manera, se puede concluir, de acuerdo con Marisol Perilla (2013, p. 241), que el capital social va más allá de las inversiones tradicionales en capital físico o humano, centrándose en las prácticas informales de conducta, derivadas de valores integradores de relación basados en la reciprocidad y la confianza.

\section{SURGIMIENTO DE NUEVOS RIESGOS EN UN MUNDO INTERCONECTADO}

A la enunciada problemática interna de los Estados, se le suma la rapidez de los cambios que ha conllevado nuevos riesgos, provocando la sensación de vivir en un mundo sin fronteras, en el que los individuos, los grupos y las naciones se hacen más interdependientes. Algo en lo que influyen mucho los avances tecnológicos, facilitando las interconexiones y la comunicación entre las personas, para acelerar todas las actividades humanas.

En este proceso, Anthony Giddens (2002, p. 89) resalta el crecimiento de formas de gobierno internacionales y regionales, como es el caso de las Naciones Unidas y la Unión Europea, ligadas por directivas, reglamentos y sentencias judiciales emitidas por organismos comunes. Escenario en el que también toman especial protagonismo las organizaciones intergubernamentales (OIG) $y$ las no gubernamentales (ONG) de tipo internacional, en la creación de una normatividad internacional que busca una justicia global con el fortalecimiento de los derechos humanos y el medioambiente, pero de igual forma, regula las relaciones comerciales y financieras en el ámbito internacional. Esto representa un desafío para los gobiernos que, en este escenario, se ven obligados a afrontar problemas ecológicos y desigualdades dentro de las sociedades y entre ellas. 
Esta reducción del espacio geográfico, también ha motivado la proliferación del crimen transnacional, que sin lugar a dudas es uno de los mayores retos que afronta la seguridad internacional desde el siglo XvI (Levi, 2005, p. 98), el cual, como industria en expansión, ha venido creando cada vez más problemas de jurisdicción legal y de investigación que afectan a todos los Estados. Lo anterior obedece a la liberación económica y comercial, a la desregulación parcial de la industria, a los progresos tecnológicos en comunicaciones, a los servicios de mensajería no gubernamentales, al transporte y la distribución; se observa aquí que la dinámica económica ha implicado, en palabras de Berdal y Serrano (2005, p. 14), el relajamiento de restricciones a las transacciones transfronterizas de todo tipo, combinándose así las condiciones, para crear nuevas estructuras de oportunidad para quienes participan en mercados criminales.

Estas organizaciones criminales organizadas, en un comienzo obedecían a una lógica de control de monopolios que incluía la violencia para cumplir este propósito, pero ahora, ante la nueva situación global, cada vez cooperan más entre ellos para alcanzar sus metas comunes (Williams, 2005, p. 108). Esto fue una preocupación que condujo a que en diciembre de 1990, la Asamblea General de las Naciones Unidas aprobara los tratados modelo de extradición (Resolución de la Asamblea General 45/116, 14 de diciembre de 1990), sobre asistencia mutua en asuntos delictivos, transferencia de ganancias delictivas y transferencia de la supervisión de transgresores; posteriormente, el Secretario General convocó una Reunión Ministerial sobre la
Creación de un Programa Efectivo de las $\mathrm{Na}$ ciones Unidas para la Prevención del Delito y la justicia Penal en Versalles (Resolución de la Asamblea General 45/108, 14 de diciembre de 1990), determinando un nuevo programa que se debería centrar en zonas específicas, para dirigir los esfuerzos de ayuda oportuna y práctica a los miembros de la ONU.

Así se conformó una de las principales conferencias mundiales de ministros sobre el crimen transnacional organizado, celebrada en Nápoles en noviembre de 1994, que reunió a más de 2000 participantes y delegaciones de 142 Estados, donde se aprobó por unanimidad la Declaración Política de Nápoles y el Plan de Acción Global contra el crimen transnacional organizado (Resolución del Consejo Económico y Social, 1992/22), que propuso la necesidad de una acción global contra el crimen transnacional organizado, instando a los países a armonizar sus legislaciones, y a asegurar que sus sistemas de justicia penal tuvieran la capacidad de impedir y controlar el fenómeno delincuencial. Para lo cual incluso se estableció la necesidad de crear fondos especiales a fin de ayudar a los países en vías de desarrollo. Posteriormente, en noviembre del 2000, la Asamblea General de las Naciones Unidas, aprobó la Convención Contra el Crimen Transnacional Organizado, junto con el protocolo adicional sobre el tráfico de personas, y el tráfico y el transporte de migrantes, y también un tercer protocolo contra la fabricación ilícita y tráfico de armas de fuego el 31 de mayo del 2001 (Vlass, 2005, p. 134).

Esto ha conllevado la conformación de alianzas entre instituciones de seguridad estatales, que han conjugado esfuerzos para 
combatir el crimen internacional organizado; incluso, esta cooperación ha suscitado muchas veces tensiones y fricciones, por celos entre las agencias o por concepciones diferentes sobre la forma de afrontar la amenaza. Esto ha hecho que conglomerados globales del crimen cooperen entre ellos para adueñarse de los mercados ilegales. Dificultando esta labor, las alianzas entre criminales, políticos y el aparato de seguridad de los Estados, en consecuencia las respuestas a las emergentes modalidades del delito son lentas y vacilantes por parte de los gobiernos, lo que hace difícil toda intervención o análisis al no poder separar lo criminal de la agenda política.

De esta manera, el crimen transnacional prolifera y se convierte en una amenaza para la seguridad nacional de los Estados, situación que se agrava porque al no ser eficientes las estrategias y los controles implementados, los criminales se adaptan a las circunstancias ante las prohibiciones de determinados bienes y servicios, surgiendo nuevos mercados ilegales. Esto conlleva la obligatoriedad, de que al establecer controles también se aumente la capacidad estatal para hacerlos efectivos, porque de lo contrario, se generan vacíos de poder y condiciones de anarquía. Al respecto, Mónica Serrano (2005, p. 31) observa que allí donde el sistema legal judicial no ejerce su poder, surge el riesgo de que los grupos criminales organizados desarrollen y desempeñen funciones públicas.

Por otra parte, la internacionalización de las leyes penales y políticas prohibicionistas ha sido, paradójicamente, una de las causas que explican el surgimiento del crimen transnacional organizado, porque esas medidas, en lugar de encontrar una debida obediencia, han creado la oportunidad para que personas que realizan actividades ilícitas desplieguen actividades a fin de satisfacer una persistente demanda de bienes y servicios prohibidas por la normatividad internacional. Además, la fragilidad y apertura de las fronteras ha generado variaciones en los gravámenes de impuestos y de prohibición, creando problemas de jurisdicción legal que elevan los costos de investigación y hacen lentos e inefectivos los controles estatales. Se devela así, que las diferencias entre los sistemas legales, tanto en la definición sustancial de los delitos como en la eficacia del aparato penal, tienen también repercusión en la magnitud de los incentivos y oportunidades delictivas (Serrano, 2005, p. 33).

Para Peter Andreas (2005, p. 65), lo que cambió en el siglo $\mathrm{xx}$, fue que aparecieron leyes ambiciosas y aparatos para su ejecución coercitiva a escala nacional, que coincidieron con un conjunto de regímenes de prohibición a escala internacional, encaminados a erradicar actividades mercantiles consideradas indeseables por los Estados más poderosos, terminando por imponer estrategias y modelos que no eran coherentes con la realidad de los países en desarrollo, y que nunca atacaron las causas que originaban los procesos ilícitos, como ocurrió en Colombia con el concepto represivo de Seguridad Nacional. En palabras de Michel Levi (2005, p. 97), para comprender el componente transnacional, "lo que se necesita es una conjunción de la oportunidad criminal que ofrece un transgresor criminal motivado y un guardián negligente". 
Adicional a la implementación acertada de estrategias de acuerdo con las características sociales, económicas y políticas, también se deben tener en cuenta las capacidades estatales, por un lado, y, por otro, la legitimidad de la norma. Por ello, como indica Mónica Serrano (2005, p. 34), se debe hacer hincapié en que el debate sobre políticas de prohibición y penalización no es solo del ámbito de especialistas y teóricos, sino que este también incumbe a la opinión pública, porque el delito mantiene una relación directa con la sociedad, partiendo incluso de que la definición de lo lícito o ilícito es el resultado de procesos históricos y políticos. Se deduce, entonces, que lo trascendental no son las políticas de prohibición, sino si estas son aceptadas y si se está en la capacidad de exigir su cumplimiento.

De igual manera, el problema de la legitimidad ha de entrar inevitablemente en la discusión sobre prohibición y penalización, porque cuando la ley está en desacuerdo con el espectro de las actitudes sociales, las oportunidades para el crimen organizado tenderán a aumentar. Interpretándose, por consiguiente, que en la medida que aumenta la tensión entre la ley y la legitimidad social, el costo de implicarse en lo que se considera ilegal disminuirá, y, por el contrario, el costo de aplicación de la ley aumentará. Por tanto, concluye Mónica Serrano (2005, p. 35), mientras exista divergencia en la definición de lo legal por la sociedad y el Gobierno, las políticas antidelictivas tenderán a ser inoperantes.

A esta complejidad hay que adicionar, que la dependencia económica de exportación de bienes primarios, de acuerdo con Collier y Hoffler, crea mayores factores de riesgo para la conformación de un conflicto y el desarrollo endémico de la violencia, coincidiendo con esto la Corte Constitucional en el Auto 004 del 2009, al declarar que la minería y el actuar macrocriminal presentan relaciones de funcionalidad. Es por ello, que la diversidad económica fundamentada en bienes y servicios, es la mejor alternativa para optar por un desarrollo sostenible, a fin de crear procesos de crecimiento que cuiden los medios naturales racionalizando su explotación y el reciclaje de los recursos físicos, reduciendo al mínimo los niveles de contaminación, protegiendo también las especies animales y la biodiversidad, así como manteniendo limpio el aire, el agua y la tierra.

En conclusión, en las actuales condiciones para comprender el contexto de la seguridad, se debe acudir a las ciencias sociales, económicas y políticas a fin de conocer a través de ellas los procesos de transformación que han acontecido dentro de los Estados porque, sin lugar a dudas, del orden interno de estos depende el orden internacional. De la confianza que inspire cada una de las naciones, depende que la interconexión de los Estados sea eficiente y no represente un peligro para la seguridad internacional, esto evidencia que al deslegitimarse la guerra, la seguridad ciudadana ha cobrado una importancia trascendental; ahora hay que hacer que el ciudadano se sienta protegido de los potenciales riesgos, pero también que él sea parte del proceso de construcción de la convivencia, porque de la profilaxis de sus comportamientos y actitudes depende su tranquilidad.

De esta manera, de la construcción de la seguridad con base en el realismo, se pasó a 
una edificación de esta cada vez más liberal, que no permite obviar los factores políticos, económicos, sociales, los medios de comunicación y la lógica criminal que también va adaptándose, causando que surjan nuevas demandas de seguridad que aumentan el número de factores por atender, porque ya no es suficiente con brindar la seguridad física; ahora, con las obligaciones sociales por parte de los Estados y, adicionalmente, con la globalización, surgieron nuevos espacios que hacen insuficiente la acción del Estado. Por tal motivo, los Estados deben crear alianzas para afrontar los nuevos riesgos, en los que la evolución tecnológica, los medios de comunicación y el mercado juegan un papel relevante.

Ahora hay que tener en cuenta que, ante la incapacidad del Estado para controlar las amenazas, la sociedad civil se hace protagonista, pero de igual forma lo individual asume una importancia trascendental, que hace necesario en la construcción de convivencia el respeto por la otredad. Este escenario crea la necesidad de edificar un conjunto de procedimientos que practiquen tanto las instituciones del Estado como las sociales, comprometiendo a los individuos frente a la autoridad colectiva a construir un régimen de verdad al que todos aporten con sus actos de verdad (Foucault, 2014, p. 116).

\section{REFERENCIAS}

Agudelo, M. (2013). Transformaciones en el mundo del trabajo. En Giraldo, C. Política social contemporánea en América Latina, entre el asistencialismo y el mercado (pp. 139-158). Bogotá: Desde Abajo.
Álvarez, L. (1998). Derecho internacional público. Bogotá: Pontificia Universidad Javeriana.

Andreas, P. (2005). Crimen transnacional y globalización económica. En Berdal M. y Serrano M. (comps.). Crimen transnacional organizado y seguridad internacional, cambio y continuidad (pp. 62-85). México: Fondo de Cultura Económica.

Arévalo, D.; Ciro, E. y Gutiérrez, M. (2006). Contribuciones de la historiografía al estudio de la protección social en Colombia. Invitación al diálogo interdisciplinario. En Le Bonniec, Y. y Rodríguez, O. (eds.). Crecimiento equidady ciudadania, hacia un nuevo sistema de protección social (pp. 177-194). Bogotá: Universidad Nacional de Colombia.

BARBÉ, E. (2007). Relaciones Internacionales. Madrid: Tecnos.

Bautista, J. (2013). Las dimensiones de la ciudadanía: hacia la interpretación de un debate contemporáneo. En Giraldo, C. Politica social contemporánea en América Latina, entre el asistencialismo y el mercado (pp. 197-214). Bogotá: Desde Abajo.

Bauman, Z. (2001). En busca de la politica. Buenos Aires: Fondo de Cultura Económica.

Bauman, Z. (2007). Tiempos líquidos, vivir en una época de incertidumbre. Barcelona: Tusquets.

Веск, U. (2.008). La sociedad del riesgo mundial, en busca de la seguridad perdida. Barcelona: Paidós.

Berdal, M. y Serrano, M. (2005). Introducción. En Berdal, M. y Serrano, M. (comps.), Crimen transnacional organizado y seguridad internacional, cambio y continuidad (pp. 13-26). México: Fondo de Cultura Económica.

Cabrera, M. y Fierro, J. (2013). Implicaciones ambientales y sociales del modelo extractivista en Colombia. En Garay, L. Minería en Colombia, fundamentos para superar el modelo extractivista 
(pp. 89-124). Bogotá: Contraloría General de la República.

Castells, M. (2001). La galaxia internet. Barcelona: Plaza y Janés.

Castells, M. (2006). La sociedad red: una visión global. Madrid: Alianza.

Castel, R. (2010). El ascenso de las incertidumbres, trabajo, protecciones, estatuto del individuo. Buenos Aires: Fondo de Cultura Económica.

Castells, M.; Caraça, J. y Cardoso, G. (2013). Las culturas de la crisis económica: una introducción. En Castells, M., Caraça, J. y Cardoso, G. (eds.). Después de la crisis (pp. 21-40). Madrid: Alianza.

Cavarero, A. (2009). Horrorismo, nombrando la violencia contempotánea. Barcelona: Anthropos.

Cortina, A. (2005). Alianza y contrato. Madrid: Trotta.

Chang, H. (2004). Retirar la escalera, la estrategia del desarrollo en perspectiva histórica. Madrid: Catarata.

De SousA, B. (2012). De la mano de Alicia, lo social y lo politico en la posmodernidad. Bogotá: Siglo del Hombre.

Enzensberger, H. (1994). Perspectivas de guerra civil. Barcelona: Anagrama.

Enzensberger, H. (1987). Politica y delito. Barcelona: Anagrama.

ENZENSBERger, H. (1969). La manipulación industrial de las conciencias. México: Universidad Nacional Autónoma de México.

Ferrajoli, L. (2010). Democracia y garantismo. Madrid: Trotta.

Fornel, D. (2005). Habitus y etnométodos. En ENCrevé, P. y Lagrave, R. (dirs.). Trabajar con Bourdieu (pp. 235-244). Bogotá: Universidad Externado de Colombia.

Foucault, M. (2014). Del gobierno de los vivos. Buenos Aires: Fondo de Cultura Económica.

Giddens, A. (2002). Sociología. Madrid: Alianza.
Giraldo, C. (2013). Política social contemporánea. En Giraldo, C. Política social contemporánea en América Latina, entre el asistencialismo y el mercado (pp. 9-116). Bogotá: Desde Abajo.

Giraldo, C. (2013). Del ciudadano al cliente, ciudadanía y derechos sociales en América Latina. En Giraldo, C. Política social contemporánea en América Latina, entre el asistencialismo y el mercado (pp. 173-196). Bogotá: Desde Abajo.

Grindle, M. (2002). En busca de lo político: la economía política de la formulación de políticas de desarrollo. En Meier, G. y Stiglitz, J. (eds.). Fronteras de la economia del desarrollo, el futuro en perspectiva (pp. 341-379). Bogotá: Alfaomega.

Han, B. (2012). La sociedad del cansancio. Barcelona: Herder.

Han, B. (2014). Psicopolitica. Barcelona: Herder.

Han, B. (2014). En el enjambre. Barcelona: Herder.

Hernández, D. (2006). La universalidad como fundamento para el diseño de la política social. En Le Bonniec, Y. y Rodríguez, O. Crecimiento, equidad y ciudadania, hacia un nuevo sistema de protección social (pp. 723-745). Bogotá: Universidad Nacional de Colombia.

Hernández, J. (2013). Formalización sostenible mediante la innovación. En J. Silva-Colmenares. Globalización, crecimiento y desarrollo (pp. 279305). Bogotá: Publicaciones ACCE.

Herrera, B. (2013). Colombia, inserción precaria en la economía global. En Silva-Colmenares, J. Globalización, crecimiento y desarrollo (pp. 167211). Bogotá: Publicaciones ACCE.

Новsваwм, Е. (2003). Historia del siglo XX. Barcelona: Crítica.

Jessop, B. (1999). Crisis del Estado de bienestar, hacia una nueva teoría del Estado y sus consecuencias sociales. Bogotá: Siglo del Hombre. 
JuRIS, J. (2006). Movimientos sociales en red: movimientos globales por una justicia global. En CAstells, M. La sociedad red: una visión global (pp. 415-438). Madrid: Alianza.

Kaldor, M. (2010). El poder y la fuerza, la seguridad de la población civil en un mundo global. Barcelona: Tusquets.

LAUTIER, B. (2006). Las condiciones políticas para la universalización de la protección social en América Latina. En Le BonNiec, Y. y RodrígueZ, O. (eds.). Crecimiento equidad y ciudadania, hacia un nuevo sistema de protección social (pp. 657-690). Bogotá: Universidad Nacional de Colombia.

Levi, M. (2005). Liberalización y crimen financiero transnacional. En Berdal, M. y Serrano, M. (comps.). Crimen transnacional organizado y seguridad internacional, cambio y continuidad (pp. 86-107). México: Fondo de Cultura Económica.

Lipovetsky, G. (2011). La era del vacío. Barcelona: Anagrama.

Meier, G. (2002). La vieja generación de economistas del desarrollo y la nueva. En Meier, G. y Stiglitz, J. (eds.). Fronteras de la economía de desarrollo, el futuro en perspectiva (pp. 1-38). Bogotá: Alfaomega.

Navarro, V. (2000). Globalización económica, poder politico y Estado del bienestar. Barcelona: Ariel.

North, D. (1993). Instituciones, cambio institucionaly desempeño económico. México: Fondo de Cultura Económica.

Nousbawn, M. (2012). Crear capacidades, propuesta para el desarrollo humano. Barcelona: Paidós.

PAstor, J. (2011). Curso de derecho internacional público y organizaciones internacionales. Madrid: Tecnos.

Pearson, F. y Rochester, J. (2000). Relaciones internacionales: situación global en el siglo XXI. Bogotá: McGraw Hill.
PaVarini, M. (2006). Seguridad frente a la criminalidad y gobierno democrático de la ciudad, "una visión entre el centro y el margen”. En Pavarini, M., Pérez, A. y Tagle, T. Seguridad pública, tres puntos de vista convergentes (pp. 11-99). México: Coyoacán.

Pérez, A. (2006). La prevención delictiva en un ambiente de conflicto social. En Pavarini, M., Pérez, A. y Tagle, F. Seguridad pública, trespuntos de vista convergentes (pp. 111-224). México: Coyoacán.

Perilla, M. (2013). Una aproximación conceptual a las políticas de lucha contra la pobreza. En GIRALDO, C. Politica social contemporánea en América Latina, entre el asistencialismo y el mercado (pp. 215-276). Bogotá: Desde Abajo.

Pisarelo, G. (2007). Los derechos sociales y sus garantías, elementos para una reconstrucción. Madrid: Trotta.

Ramírez, Y. (2007). El delito ecológico. Bogotá: Doctrina y Ley.

Rodríguez, O. (2006). Del patronato al aseguramiento en el sistema de protección social en Colombia: asistencia, identificación y legitimidad. En Le Bonniec, Y. y Rodríguez, O. (eds.). Crecimiento equidad y ciudadania, hacia un nuevo sistema de protección social (pp. 197-282). Bogotá: Universidad Nacional de Colombia.

Rosanvallon, P. (1995). La nueva cuestión social, repensar el Estado providencia. Buenos Aires: Manantial.

Rosanvallon, P. (2009). La legitimidad democrática, imparcialidad, reflexividad, proximidad. Buenos Aires: Manantial.

Serrano, M. (2005). Crimen transnacional organizado y seguridad internacional: cambio y continuidad. En Berdal, M. y Serrano, M. (comps.). Crimen transnacional organizado y seguridad internacional, cambio y continuidad (pp. 27-61). México: Fondo de Cultura Económica. 
Serrano, M. y Toro, M. (2005). Del narcotráfico al crimen transnacional organizado en América Latina. En Berdal, M. y Serrano, M. (comps.). Crimen transnacional organizado y seguridad internacional, cambio y continuidad (pp. 233-273). México: Fondo de Cultura Económica.

TAGLE, F. (2006). Elementos para una política inclusiva en el campo penal. En Pavarini, M., Pérez, A. y TAGLE, F. Seguridad pública, trespuntos de vista convergentes (pp. 235-294). México: Coyoacán.

Torralba, F. (2003). Cien valores para una vida plena, la persona y su acción en el mundo. Lleida: Milenio.

Valencia, A. (1994). Derecho humanitario para Colombia. Bogotá: Defensoría del Pueblo.

Valencia, A. (2007). Derecho internacional humanitario, conceptos básicos, infracciones en el conflicto armado colombiano. Bogotá: Oficina en Colombia del Alto Comisionado de las Naciones para los Derechos Humanos.
Vela, B. (2013). Los ideales de la paz, los tiempos de la guerra. Una reflexión sobre las paradojas que se suscitan en las negociaciones de paz entre el Gobierno de Colombia y la disidencia política armada como consecuencia de la transformación del mundo contemporáneo y sus paradigmas. Boletin de historia y antigüedades (856), 9-76.

VLASS, D. (2005). La convención de las Naciones Unidas contra el crimen transnacional organizado. En Berdal, M. y Serrano, M. (comps.). Crimen transnacional organizado y seguridad internacional, cambio y continuidad (pp. 131-148). México: Fondo de Cultura Económica.

Williams, P. (2005). Cooperación entre organizaciones criminales. En Berdal, M. y Serrano, M. (comps.). Crimen transnacional organizado y seguridad internacional, cambio y continuidad (pp. 108-130). México: Fondo de Cultura Económica. 